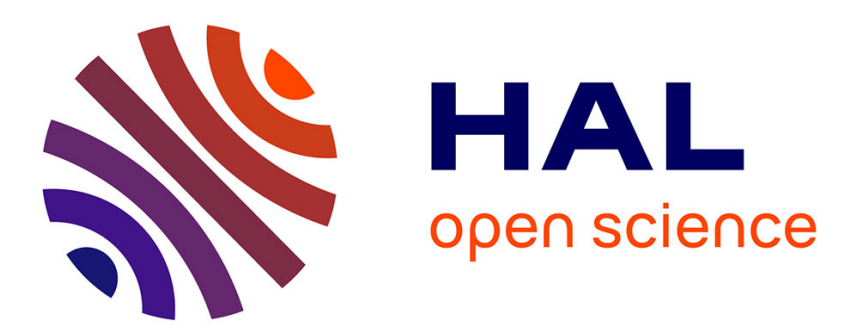

\title{
Material and Geometric Heterogeneity Consideration for Cracking Risk Prediction of Young Age Behavior of Experimental Massive Reinforced Concrete Structure
} Ponleu Chhun, Laurie Buffo-Lacarrière, Alain Sellier

\section{- To cite this version:}

Ponleu Chhun, Laurie Buffo-Lacarrière, Alain Sellier. Material and Geometric Heterogeneity Consideration for Cracking Risk Prediction of Young Age Behavior of Experimental Massive Reinforced Concrete Structure. Key Engineering Materials, 2016, 711, pp.900-907. 10.4028/www.scientific.net/KEM.711.900 . hal-01691711

\section{HAL Id: hal-01691711 \\ https://hal.science/hal-01691711}

Submitted on 24 Jan 2018

HAL is a multi-disciplinary open access archive for the deposit and dissemination of scientific research documents, whether they are published or not. The documents may come from teaching and research institutions in France or abroad, or from public or private research centers.
L'archive ouverte pluridisciplinaire HAL, est destinée au dépôt et à la diffusion de documents scientifiques de niveau recherche, publiés ou non, émanant des établissements d'enseignement et de recherche français ou étrangers, des laboratoires publics ou privés. 


\title{
Material and Geometric Heterogeneity Consideration for Cracking Risk Prediction of Young Age Behavior of Experimental Massive Reinforced Concrete Structure
}

\section{Ponleu CHHUN" a ${ }^{1,}$, Laurie BUFFO-LACARRIERE ${ }^{1, \mathrm{~b}}$ and Alain SELLIER ${ }^{1, \mathrm{c}}$ \\ ${ }^{1}$ LMDC, INSAT/UPS Génie Civil, 135 Avenue de Rangueil, 31077 Toulouse cedex 04 France \\ achhun@insa-toulouse.fr, b lacarri@insa-toulouse.fr, c sellier@insa-toulouse.fr}

Keywords: early age; shrinkage; creep; thermal strain; distributed reinforcement; scale effect; cracking

\begin{abstract}
This article presents the application of a thermo-hydro-chemo-mechanical (THCM) model to a real complex structure of reactor confinement (mock-up VERCORS from EDF) by taking into account the specificities of the construction (construction consequences), the distributed reinforcements and the material heterogeneity of massive structure. The experimental campaigns were conducted during and after the construction of VERCORS. The early-age behavior of concrete is first modelled based on a multiphasic hydration model to ensure the thermal evolution. Then a 3D mechanical model is used to predict the consequences of hydration, temperature and water variations on mechanical behavior. An alternative approach to consider the structural effect of distributed reinforcement without explicit meshing of reinforcements is implemented and is able to reproduce the influence of reinforcement on the crack patterns. Moreover, the "Weakest link localization” method is also adapted to deal with a probabilistic scale effect due to the material heterogeneity of massive structure. It permits to assess directly the most likely tensile strength which can treat the first crack in softening part of the loaded volume of structures.
\end{abstract}




\section{Introduction}

The work presented here was performed in the framework of the French national project ANRMACENA-PIA. This study is part of the project dealing with the early-age behavior of reinforced concrete structure under thermos-hydro-chemo-mechanical (THCM) loads. One of the objectives of this component was to test and validate the THCM models available in the French scientific community for predicting the early-age crack patterns on a real experimental mock-up of a reactor, called VERCORS, thanks to EDF. The particularities of this study focus on the modelling of reinforced concrete and the massive structure.

The main problem of prediction of cracking in large structures is the assessment of tensile strength for ductile materials with softening behavior. The probability of defects is more presented as the volume of structure increases. This phenomena is well known as the Weibull scale effect and can be modelled using the Weakest link and localization method [1]. The origin of this scale effect was discussed in [2]. For a metric element, the tensile strength can be reduced by 50\% from the measured strength by means of a split test on decametric-sized specimens. That is reason that the need for considering this phenomena is necessary.

Moreover, regarding to the modelling of the early-age behavior of reinforced concrete structure, the meshing of reinforcements and time-consuming calculation are still the problems for massive structures. In the literature, there are two approaches that have been frequently used to model the reinforced concrete structure by meshing the bar elements. The first one [3] is to model a volumetric interface element of bar element that that occupies the real volume of the steel bar in the center of which a bar element is integrated with the properties of steel. The second one [4] which can be adapted to avoid the interface element is a zero thickness four-node element which relates each steel truss element with a segment superimposed with the steel element and perfectly bonded to the surrounding concrete. Even though these approaches can reproduce the bond mechanism between steel and concrete, they have their own limits such as explicit meshing of reinforcements and computation time. In order to avoid these difficulties, the structural effects of reinforcements can be considered as equivalent the ones due to orthotropic distributed reinforcements.

In this study, a THCM model initially developed in laboratory LMDC was used to predict the early-age behavior of concrete mock-up VERCORS with integration of probabilistic scale effect, accompanied by the hydration modelling in order to verify the thermal loads. Beside this, a comparison of concrete and reinforced concrete on cracking patterns is conducted following by the experimental results. 
The aim of this paper is to demonstrate the applicability of integrated models to predict early-age crack patterns on a real massive reinforced concrete structure. The massive mock-up of a reactor VERCORS was thus used in this objective.

\section{Presentation of nuclear containment mock up VERCORS}

In the framework of EDF's continuous effort on the safety and life extensions of nuclear power plants, an experimental mock-up of a reactor containment-building at $1 / 3$ scale was built at Renardieres near Paris. The so-called VERCORS [5] mock-up is a double wall containment ( $\mathrm{H}=30 \mathrm{~m}$, $\varnothing=16 \mathrm{~m})$. This mock-up was finely instrumented so that its behavior could be monitored from the beginning of the construction. The structure tested in this paper is a part of the internal containment (Fig. 1). The formulation of VERCORS concrete casted with a CEM I 52.5N cement is given in Table 1.

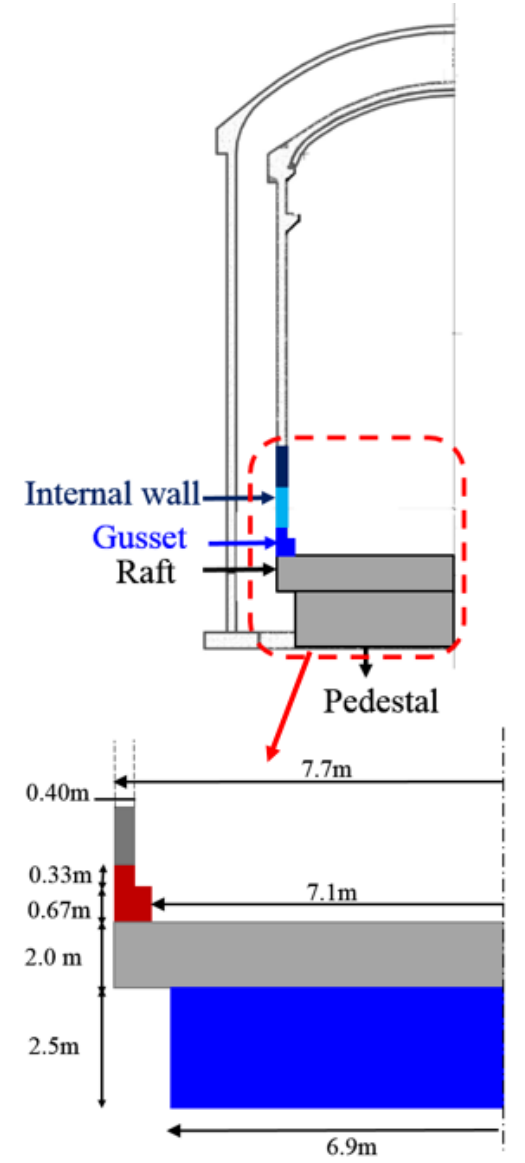

Fig. 1 : Axisymmetric section of structure

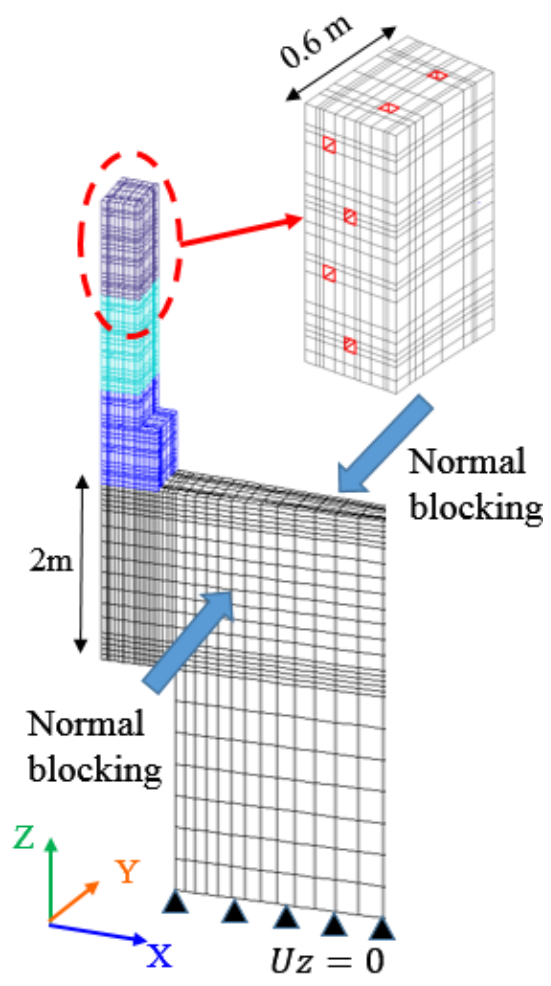

Fig. 2 : 3D mesh of the studied structure (with details of thermal and mechanical boundary conditions)

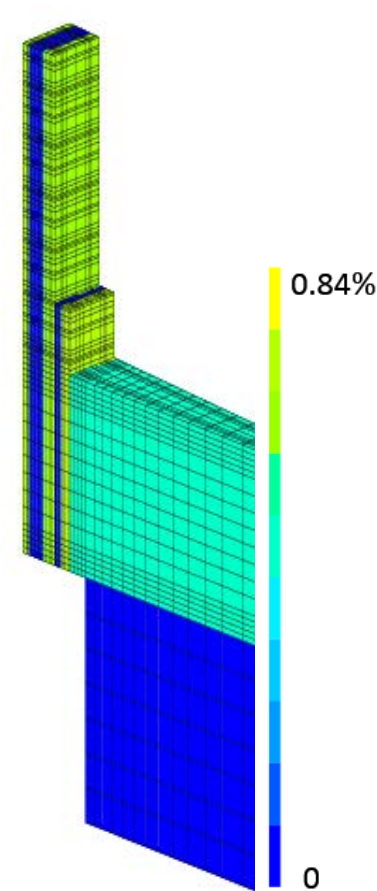

Fig. 3 : Vertical steel ratios $\left(\rho_{z}\right)$

VERCORS 
Table 1. Formulation of VERCORS concrete

\begin{tabular}{lc}
\hline & Quantities (kg/m $\left.{ }^{3}\right)$ \\
\hline Cement CEM I 52.5N CE CP2 NF Gaurain & 320 \\
Sand 0/4 rec GSM LGP1 & 830 \\
Gravel 4/11R GSM LGP1 & 445 \\
Gravel 8/16R Balloy & 550 \\
Superplasticizer Techno 80 & 2.4 \\
Effective water & 167.2 \\
\hline
\end{tabular}

\section{General presentation of THCM model-LMDC}

\section{Thermo-hydro-chemo-mechanical model}

First, the thermal behavior of the concrete structure is estimated thank to a multiphasic hydration model [6] based on the coupling between hydration, water content and temperature. Then the 3D mechanical model [7] is used to predict the consequences of hydration, temperature and water variations on mechanical behavior. This model allows to take into consideration several important phenomena such as the creep, shrinkage, thermal deformation and internal pressure effects and to estimate cracking risk. The general form of total stress in the matrix is given by equation (1)

$$
\sigma_{i j}^{m}=\left(1-D_{i j k l}\right) \tilde{\sigma}_{k l}^{m}
$$

With $D_{i j k l}$ the damage variable, $\tilde{\sigma}_{k l}^{m}$ the total effective stress (2) which depends on the effective stress in solid skeleton and interstitial phase. Regarding the solid skeleton behavior, the effective stress can be linked directly, via the material stiffness $S_{k l m n}^{0}(3)$, to the strains which consist of elastic strain $\varepsilon_{m n}^{E}$, plastic strain $\varepsilon_{m n}^{p l}$, creep strain $\varepsilon_{m n}^{C r}$, and thermal strain $\varepsilon_{m n}^{t h}$. For hydric effects, it's caused by the capillary pressure $P_{w, k l}(5)$ and can be defined by the Biot coefficient $b$ (in saturated condition) and the saturation rate $\mathrm{Sr}$.

$$
\tilde{\sigma}_{k l}^{m}=S_{k l m n}^{0}\left(\dot{\varepsilon}_{m n}^{E}-\dot{\varepsilon}_{m n}^{p l}-\dot{\varepsilon}_{m n}^{C r}-\dot{\varepsilon}_{m n}^{t h}\right)-b \cdot S r \cdot \dot{P}_{w, k l}
$$

The material stiffness $S_{k l m n}^{0}$ is a second-order tensor expressed as a function of Young's modulus $\left(E^{0}\right)$ and Poisson's ratio $\left(v^{0}\right)$.

$$
S_{k l m n}^{0}=f\left(E^{0}, v^{0}\right)
$$

The Young's modulus varies depending on the hydration degree and can be determined thank to the De Schutter's [8] equation as follows: 


$$
E^{0}(\alpha)=\left\{\begin{array}{cl}
0 & \text { if } 0 \leq \alpha \leq \alpha_{t h r} \\
E_{t h} \times\left(\frac{\alpha-\alpha_{t h r}}{1-\alpha_{t h r}}\right)^{n_{E}} & \text { if } \alpha>\alpha_{t h r} \text { and } \alpha<1
\end{array}\right.
$$

With $E_{t h}$ is Young modulus for the material supposed completely hydrated, $\alpha_{t h r}$ is the hydration threshold corresponding to the concrete solidification [9], $n$ is the non-linearity coefficient. The De Schutter's equation form (4) can be used for the mechanical property such as compressive strength and tensile strength.

The equivalent capillary pressure can be modelled with two parameters ( $M_{\text {shr }}$ and $k$ ) thank to Van-Genuchten model [10] as a function of the saturation rate $\mathrm{Sr}$ as follows:

$$
P_{w, k l}=-M_{s h r}\left[S r^{(-1 / k)}-1\right]^{(1-k)}
$$

\section{Homogenized behavior law of a reinforced concrete}

The homogenized behavior law of the reinforced matrix is uniaxial and the resulting stresses are modified only in the direction $\left(\vec{V}_{\hat{\imath}}\right.$, with $\left.i \in[1,2,3]\right)$ as follows:

$$
\sigma_{i i}=\left(1-\rho_{i}\right) \sigma_{i i}^{m}+\rho_{i} \sigma_{i}^{r}
$$

With $\rho_{i}$ the reinforcement rate in each direction corresponding to ratio of cross section of reinforcement and the matrix cross section in the same direction $\vec{V}_{\hat{\imath}} \cdot \sigma_{i i}^{m}$ the normal stress in the matrix (1) and $\sigma_{i}^{r}$ the axial stress in the reinforcement computed through the behavior law of reinforcement which is élasto-plastic with a perfect plasticity.

$$
\sigma_{i}^{r}=E^{r}\left(\varepsilon_{i}^{r}-\varepsilon_{i}^{p l}\right)
$$

Where $E^{r}$ the reinforcement Young modulus, $\varepsilon_{i}^{r}$ the axial strain in the reinforcement, $\varepsilon_{i}^{p l}$ the plastic strain of reinforcement.

\section{Probabilistic scale effect}

After receiving the data on mechanical properties from different partners in MACENA project, we can notice a remarkable dispersion of the values in Fig. 4, especially at 28 days. The tensile strength is an important criteria to treat the cracking of concrete, but it's hardly to find its reliable value despite a large amount of samples because there is another impact of material heterogeneity which is unavoidable particularly for massive structure like reactor VERCORS. Fortunately, the random distribution of tensile strength leading to a probabilistic scale effect can be dealt with an alternative approach, called “Weakest Link Localization” [1] thank to the Weibull's concept. This approach is capable to assess directly the most likely tensile strength, which treats the first crack in a 
softening part of the loaded volume of structures, via the following law (8). The scale effect can be presented through the curve (Fig. 4d) that shows the diminution of tensile strength when the size of volume increases.

$$
\frac{R_{t(M)}}{R_{t}^{r e f}}=\left(\frac{V_{r e f}}{V_{e q(M)}}\right)^{1 / m}
$$

In Eq. (8), $R_{t(M)}$ is a tensile strength at point M. $R_{t}^{r e f}$ is the average tensile strength measured on a specimen with the loaded volume $V_{\text {ref }} . m$ is the Weibull exponent depending on the coefficient of variation $C^{v}$ of experimental results:

$$
m \approx \frac{1}{10}\left(\frac{12}{C^{v}}-2\right)
$$

And the equivalent loaded volume $V_{e q(M)}$ is defined as follows:

$$
V_{e q(M)}=\frac{1}{\beta_{\max }} \int_{\Omega} \beta \cdot \psi(M) d \Omega
$$

With $\psi(M)$ the weighting function (11), $\beta$ the loading index (12), $\Omega$ the structure, and $d \Omega$ a structure infinitesimal volume.

$$
\psi(M)=\exp \left[-\frac{1}{2}\left(\frac{d(M)}{l_{c p}}\right)^{2}\right]
$$

Where $d(M)$ the distance between point $\mathrm{M}$ and its nearby point, $l_{c p}$ the characteristic length of probabilistic weighting function whose usual value is $0.5 \mathrm{~m}$ for a concrete.

$$
\beta=\left(\frac{\max \left(\sigma_{I}, 0\right)}{R_{t}^{\text {ref }}}\right)^{m}
$$

With $\sigma_{I}$ the principal tensile stress

\section{Application to structure VERCORS}

\section{Determination of model parameters}

During the project, the thermal and mechanical characterization tests of concrete were conducted in situ and in laboratories, which allowed the fitting of model with precision. The three fitting parameters of the multiphasic hydration model were determined by an inverse analysis on an adiabatic test conducted at laboratory CEBTP. The thermal parameters of concrete used in MACEA project were determined experimentally and provided in Table 2. 
Table 2. Thermal and hydric parameters

\begin{tabular}{lc}
\hline Thermal parameters & Quantities \\
\hline Thermal conductivity $[\mathrm{W} /(\mathrm{m} . \mathrm{C})]$ & 1.965 \\
Concrete density $\left[\mathrm{kg} / \mathrm{m}^{3}\right]$ & 2370 \\
Specific heat $\left[\mathrm{J} / \mathrm{kg} .{ }^{\circ} \mathrm{C}\right]$ & 880 \\
\hline
\end{tabular}

The instantaneous characteristics of concrete (strengths, Young's modulus) increase as the material hardens. So the De Schutter's law (4) is adopted to consider the effect of hydration on these mechanical properties. The parameters used for this law are shown in Table 3 with illustration of the evolution of characteristics in Fig. 4a, 4b,4c.

Table 3. Data for De Schutter's evolution law

\begin{tabular}{cccc}
\hline$i$ & $X_{t h}$ & $n_{i}$ & $\alpha_{t h r}$ \\
\hline$R_{c}$ & $75 M P a$ & 1 & \\
$R_{t}$ & $7 M P a$ & 1 & 0.17 \\
$E$ & $52 G P a$ & 0.66 & \\
\hline
\end{tabular}




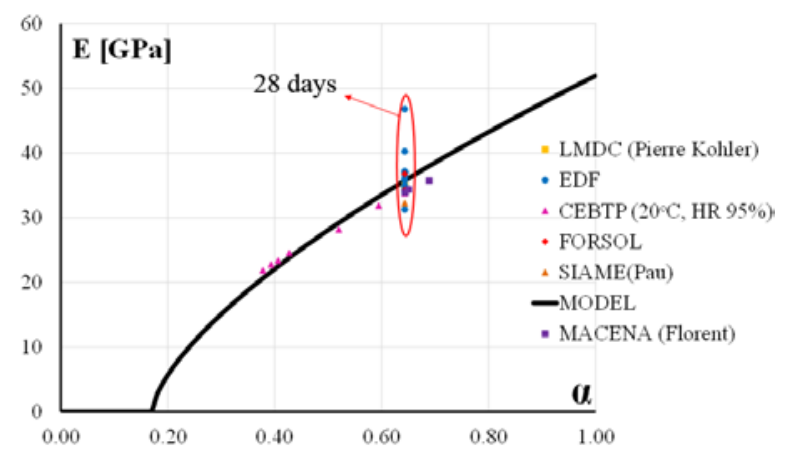

(a)

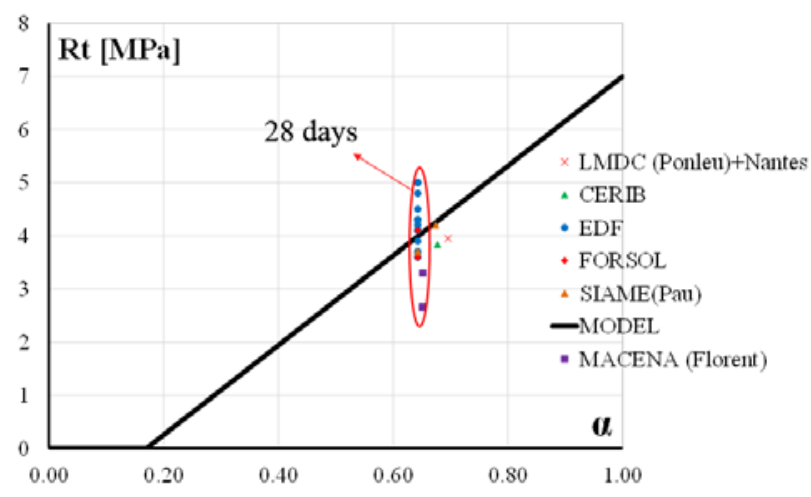

(c)

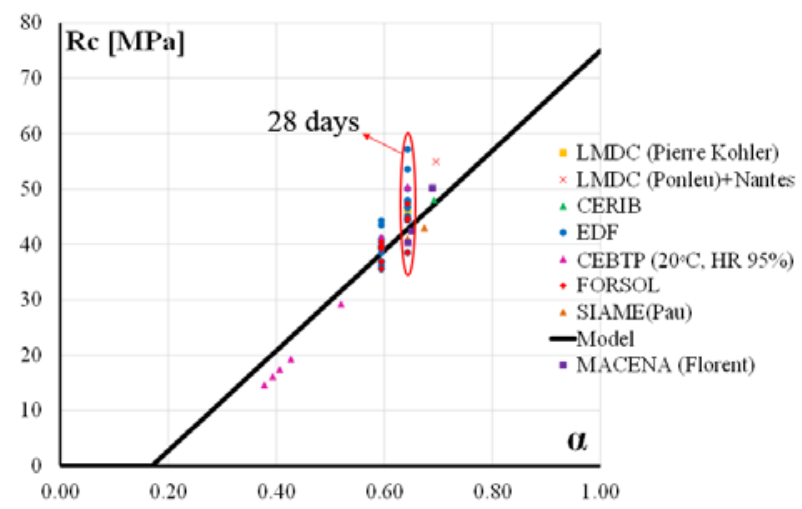

(b)

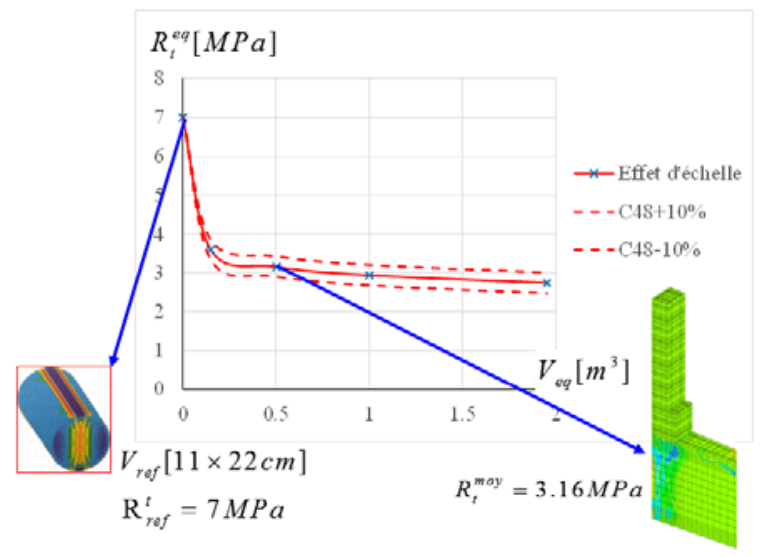

(d)

Fig. 4 : Evolution of instantaneous characteristics due to hydration development (a, b, c: experimental results from different partners in MACENA project), (d) Evolution of tensile strength due to scale effect

\section{Mesh and boundary condition}

The studied structure corresponds to a radial piece of cylindrical internal containment with angle of $4.5^{\circ}$ which contains pedestal, raft, gusset and interior wall. It was modelled using a 3D mesh with 13, 178 cubic elements. The particularities of this structure are also considered such as prestressed duct in order to see its impact on the cracking. The 3D mesh of the entire structure and the detail of thermal and mechanical boundary conditions are summarized in Fig. 2. In this figure, it can be seen that each component of structure is casted at different stage. And this particular care was also taken when modelling the concrete structure in order to ensure good thermal boundary conditions. The initial temperature of concrete casted at each stage is considered as the initial condition. The daily variation of external temperature was used directly in our thermal modelling as a convective boundary condition. During the formwork of each stage, the equivalent convective coefficient of the formwork was used and it was evaluated by means of a serial model. After formwork removal, only the free convective coefficient which was estimated due to wind and given in the project was used. Particularly 
as this mock-up was built at $1 / 3$ scale, the gusset was heated intentionally to accelerate the drying of the concrete in order to obtain the more representative behavior of real reactor.

Concerning mechanical boundary conditions, the vertical displacement of pedestal was fixed and the two lateral surfaces of entire structure were blocked in their normal direction.

\section{Thermal result}

Considering the equivalent and free convective coefficients for the period of formwork and the external temperature variation plus the heating condition at gusset, the thermal results of modelling are in good agreement with the experimental measurements (Fig. 5).

The hydration model used in this study was further validated previously on other structures ([3], [6], [11]) and the comparison with the experimental results was only conducted to ensure that the THCM loading was correct.

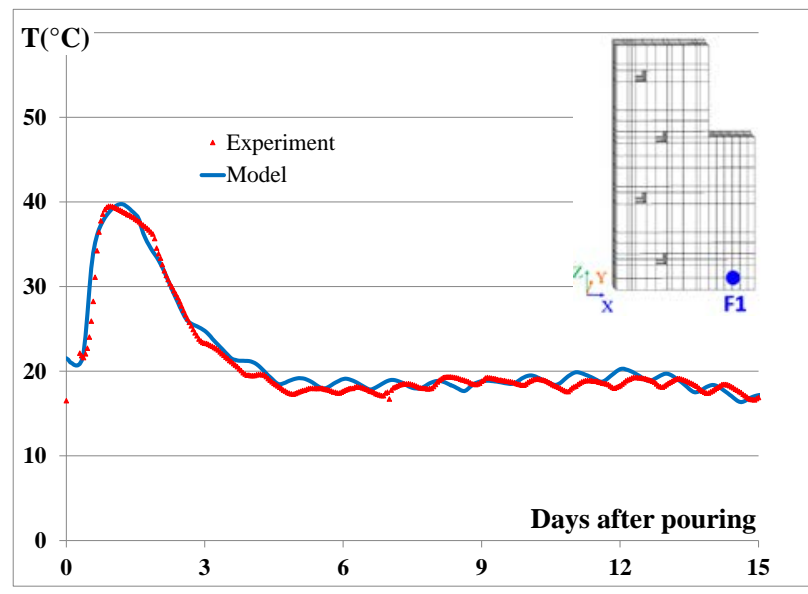

(a) Inner face temperature

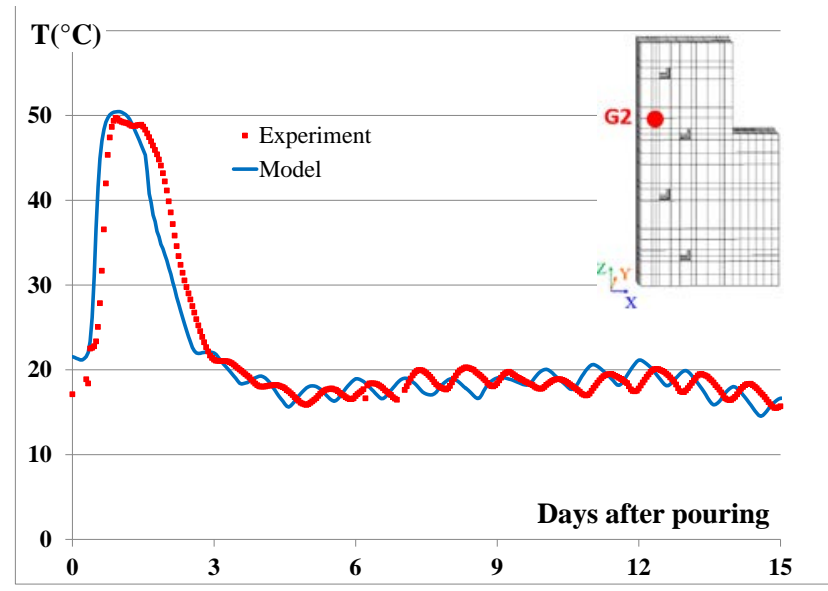

(b) Outer face temperature

Fig. 5 : Numerical and experimental results for thermal evolution of gusset

\section{Mechanical result}

The numerical results obtained from the THCM modelling were successfully compared with experimental results, and the results of crack patterns of gusset were presented in Fig. 6. This configuration can illustrate clearly the influence of reinforcement through the difference in the crack pattern of concrete and reinforced concrete that were reproduced by adapting the distributed reinforcements. Fewer, but more open, cracks existed for concrete structure, which show the structural effect of reinforcements on the crack patterns. Beside this, we note the cracks occurred preferentially face to the prestressed duct, which shows the impact of the prestressed ducts on the crack patterns. Last but not least, the crack patterns from numerical model are also globally well reproduced in comparison to the experimental results (vertical crack patterns) observed on mock-up VERCORS. 
According to observation on the intrados of gusset, there is the heterogeneity of cracking but they are more open at level $-0.33 \mathrm{~m}$, which is in agreement with the numerical results. For the extrados, the crack width was more important near the middle which is also similar to the numerical results.

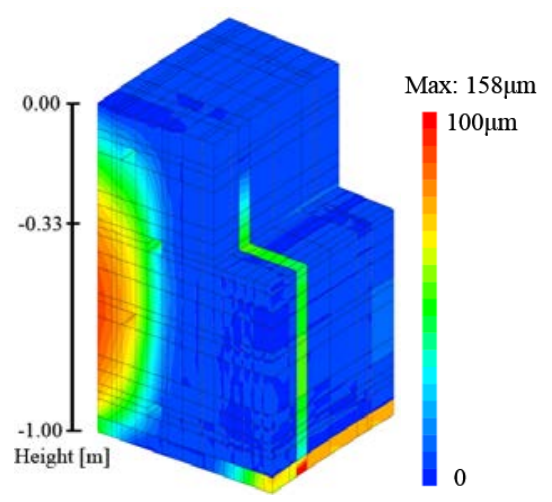

(a)

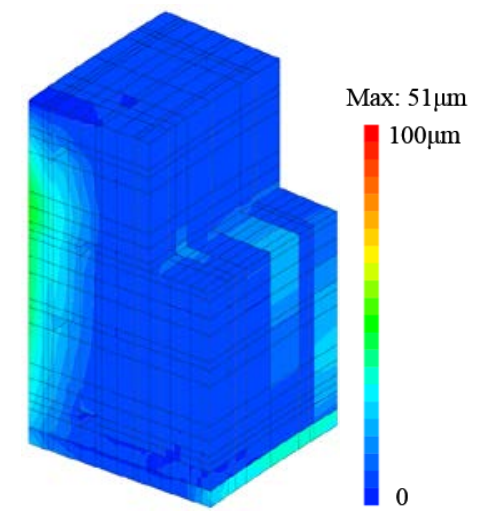

(b)

Fig. 6 : Comparison of crack pattern of (a) concrete and (b) reinforced concrete, at 5 days after pouring

\section{Conclusion}

The work presented here was about a numerical approach based on THCM model which enables a prediction of behavior of reinforced concrete structure at early age. This model was applied to a real massive structure VERCORS.

A good prediction of the temperature evolution in the gusset was obtained. Then, the numerical applications were tested on the structure with the same thermal loading but different reinforcement (zero and real steel ratios). It highlighted the interest of modelling the distributed reinforcement without explicit meshing of reinforcements. It allowed to consider the structural effects of reinforcement as the reproduction of the different cracking pattern of a concrete structure. Moreover, these applications mentioned the implementation of Weakest Link Localization to consider the probabilistic scale effect due to the material heterogeneity of massive structure which was also the case for mock-up VERCORS.

\section{Acknowledgements}

We are grateful to EDF for construction of VERCORS and the investigations and results reported here. The French National Research Agency (ANR) is acknowledged for their financial support to the research project MACENA. Last but not least, we also thank to CEA for providing the finite element code CASTEM. 


\section{References}

[1] A. Sellier and A. Millard, "Weakest link and localisation WL 2: a method to conciliate probabilistic and energetic scale effects in numerical models,” Eur. J. Environ. Civ. Eng., pp. 115, 2014.

[2] Z. P. Bažant and A. Yavari, "Is the cause of size effect on structural strength fractal or energeticstatistical?,” Eng. Fract. Mech., vol. 72, no. 1, pp. 1-31, 2005.

[3] L. Buffo-Lacarrière, A. Sellier, and B. Kolani, “Application of thermo-hydro-chemo-mechanical model for early age behaviour of concrete to experimental massive reinforced structures with strain-restraining system,” Eur. J. Environ. Civ. Eng., vol. 18, no. 7, pp. 814-827, 2014.

[4] C. Mang, L. Jason, and L. Davenne, “A new bond slip model for reinforced concrete structures: Validation by modelling a reinforced concrete tie,” Eng. Comput., vol. 32, no. 7, pp. 1934-1958, 2015.

[5] “EDF VeRCoRs Project 2016.” [Online]. Available: https://fr.amiando.com/fb/EDF-vercorsproject.html. [Accessed: 29-Jan-2016].

[6] L. Buffo-Lacarrière, A. Sellier, G. Escadeillas, and A. Turatsinze, "Multiphasic finite element modeling of concrete hydration,” Cem. Concr. Res., vol. 37, no. 2, pp. 131-138, 2007.

[7] A. Sellier, S. Multon, L. Buffo-Lacarrière, T. Vidal, X. Bourbon, and G. Camps, “Concrete creep modelling for structural applications: non-linearity, multi-axiality, hydration, temperature and drying effects,” Cem. Concr. Res., vol. 79, pp. 301-315, 2016.

[8] G. De Schutter and L. Taerwe, "Degree of hydration-based description of mechanical properties of early age concrete,” Mater. Struct., vol. 29, no. 6, pp. 335-344, Jul. 1996.

[9] J. M. Torrenti and F. Benboudjema, "Mechanical threshold of cementitious materials at early age,” Mater. Struct., vol. 38, no. 3, pp. 299-304, 2005.

[10] M. T. van Genuchten, “A Closed-form Equation for Predicting the Hydraulic Conductivity of Unsaturated Soils1,” Soil Sci. Soc. Am. J., vol. 44, no. 5, p. 892, 1980.

[11] L. Buffo-Lacarrière, A. Sellier, A. Turatsinze, and G. Escadeillas, "Finite element modelling of hardening concrete: application to the prediction of early age cracking for massive reinforced structures,” Mater. Struct., vol. 44, no. 10, pp. 1821-1835, 2011. 